\title{
Research on Qualified Vocational Training Development in the Context of Digitalization ${ }^{\dagger}$
}

\author{
Marius Miklos Veres ${ }^{1, *}$, Cristina Veres ${ }^{2}$, Antoaneta Maria Rauca ${ }^{1}$, Liviu Onoriu Marian ${ }^{1}$ \\ and Ancuta Sigmirean ${ }^{1}$ \\ 1 Department of Management and Economic Engineering, Technical University of Cluj-Napoca, \\ 400114 Cluj-Napoca, Romania; tonia_0204@yahoo.com (A.M.R.); liviu.marian@yahoo.com (L.O.M.); \\ ancuta_sigmirean@yahoo.com (A.S.) \\ 2 Department of Industrial Engineering and Management, University of Medicine, Pharmacy, Science and \\ Technology of Tîrgu Mureș, 540142 Tîrgu-Mureș, Romania; harea.cristina@yahoo.com \\ * Correspondence: mariusveres@yahoo.com \\ + Presented at the 14th International Conference on Interdisciplinarity in Engineering-INTER-ENG 2020, \\ Târgu Mureș, Romania, 8-9 October 2020.
}

Published: 21 January 2021

\begin{abstract}
From a strategic point of view digitalizing the economy in the near future means that it's necessary, from now on, to change the focus on digital skills because at the moment almost all jobs require some level of digital knowledge from employees. Although digitalization brings a lot of advantages, the vocational education and training cannot be entirely digitalized as qualified vocational development has to maintain its traditional approach in order remain efficient and most importantly attractive. This paper describes the results of a focus group conducted in Mures County, Romania on the topic of digitalization with the aim to offer an overview image on vocational education and training challenges in the current context.
\end{abstract}

Keywords: challenges; digitalization; training development; vocational education and training

\section{Introduction}

Digitalization is a hot topic in the context of the current pandemic, we are at the dawn of the digital age in which the fundamental systems of society are changing radically in a fast time. Digitalizing the economy in the near future means that from a strategic point of view it is necessary, from now on, to change the focus on digital skills because at the moment almost all jobs require some level of digital knowledge from employees. Moreover, the human resource will have to be trained in such a way that it can collaborate with robots and artificial intelligence. Moving the focus is a challenge of great importance and immediate relevance. The transformation of the economic system will be complex, so the appropriate adaptation of the qualified vocational training system to the new conditions will be essential.

The fourth industrial revolution represents the reorganization of society, more precisely a superior collaboration between humanity and digital technologies that will lead to a superior dynamic of organizations in general. This dynamic can be characterized by flexibility, reaction speed, infinite analysis and simulations, intelligent decisions, control.

It is therefore clear that the labour market is already feeling the wind of change, a change brought about by rapid technological innovations, on the one hand, and by human resources, the development and training of which is required to be much more dynamic, on the other. The level of expectations regarding the skills and individual values of employees will increase. Currently, the challenges of combining these two factors of change are very significant. The transformation of the economic system 
will be complex, so the appropriate adaptation of the qualified vocational training system to the new conditions will be essential.

This article aims to highlight the strategic importance of digitalization in professional development, the challenges posed by it but also its limitations, offering an overview image on vocational education and training challenges in the current context.

\section{Digitalization: Factors, Challenges and Limitations}

Digital age learning represents a series of concerns which have to be addressed by policymakers, who attempt to plan education and training in such a way as to improve competences imperative for employment, personal development or social inclusion. "A new skills agenda for Europe" emphasized the difficulties of the employers in hiring skilled people with an appropriate level of digital competences, entrepreneurial and innovative capabilities. Almost $40 \%$ of European enterprises are facing a shortage of highly skilled personnel able to use digital technologies in the context of globalized economy.

The European Commission with its multi annual plan named "A new skills agenda for Europe" predicts a change of paradigm as skill needs will vary across different sectors of the economy which emerge or radically change as a result of technological developments. The just-in-time supply of the right skills will empower competitiveness and innovation. Investments will also utterly depend on the availability of high-end skills [1].

The accessibility of the digital technologies is the key to reduce the learning gap between education and the challenges of a dynamic and interconnected world. "The Digital Education Action Plan" underlines that digital innovation in education systems will improve the quality of education systems. The education must use more efficiently the digital technology for teaching and learning, to develop digital skills and competences relevant for the digital transformation of Europe, and to improve education [2].

More than ever people started to realize that digitalization is a solution and even though statistics show that the degree of digital literacy is very low in Romania, the adaptability and the employability provided by digital skills and competences in general should ensure that extra motivation from all beneficiary to work harder to overcome this drawback. Nevertheless, the digitalization projects and qualified vocational training systems must consider the digital literacy of our country to produce long-term change. Digital solution can only work if the systems that we have in operation make them functional. Without strong training systems we will not be able to achieve superior sustainable performance. No solution will work unless run in a suitable environment. The economic environment imposes new and updated requirements, norms, rigors and standards, therefore close collaboration and immediate communication between economic and educational organizations is imperative in order to upgrade the vocational training system so that it can meet the challenges.

In the short term, the field of health and education are a priority for digitalization, so the reaction speed of the institutions involved will be essential. Human resource skills and digital infrastructure are key factors in implementing digitalization. Digitalization ensures adaptability and employability for the masses. Digitalization is a huge opportunity for all value-producing areas, but this opportunity can only be exploited through the early implementation of comprehensive, long-term strategies and programs that focus on training the professional skills of human resources, that is, adapting them to new requirements.

The adoption of technologies has not led to the abolition of jobs but has created new opportunities that have harnessed creativity and human potential in a more satisfying and motivating way. The new hybrid skills not only capitalize on technology but combine it with the human dimension. The result is a new type of contribution, responsibility and leadership [3].

In this time of crisis some institutions have completely cut off budgets destined for education and training, including the digital one; however, it's obvious that the economy resets and as a result there will be many professional reconversions in the next period with an emphasis on digital skills and competences. 
Vocational education and training need to be heavily funded through investment programs where all stakeholders must assume part of the financing. In this regard, effective co-financing system for these programs must be implemented, the lack of such systems may lead to major dysfunctions in their activity. Qualified vocational training infrastructure is deficient, but positive steps can be made. The stakeholders should develop regional or local heavily digitalized technologic workshops in which the professional training of the human resource is based on hybrid methodology and where the digital and the hands-on approach are harmoniously combined. In these smart centres various activities such as collaboration with robots, 3D technologies or virtual reality must be applicable.

A strong political signal, an ambitious answer and financial impulse materialized through a major recovery plan called "Europe's moment: Repair and Prepare for the Next Generation". European Commission President Ursula von der Leyen said that this crisis represents a good opportunity to invest in Europe's future, also emphasizing that the European Green Deal and digitalization will boost jobs and growth [4].

Funds will be channelled through various EU Programmes like A Skills Agenda for Europe and A Digital Education Action Plan, which will ensure digital skills for E.U citizens.

Because this is a new, recently introduced field, digitalization has its limitations and challenges; we need to clarify its operating principles so that we can take full advantage of its advantages and potential. Vocational training institutions, including Romanian ones, are still failing to sufficiently prepare human resources for this new industrial revolution, also called digitalization, and companies are failing to take full advantage of the benefits that digitalization can generate. The reasons for this situation are many, but the most important factor that generates this desolate situation is that no one fully understands what skills and abilities ensure success in an era that is expected to be dominated by digital technologies and artificial intelligence.

Although digitalization brings a lot of advantages, the vocational education and training cannot be entirely digitalized as qualified vocational development has to maintain its traditional approach in order remain efficient and attractive. Vocational training must remain a hands-on experience otherwise it risks becoming abstract and distant, and the pleasure for learning will be partially lost. Physical contact and social interaction strengthen working relationships, help people learn from one another by sharing experience and knowledge which helps the company to progress. These aspects cannot be achieved in a digital environment [5].

Researchers have concluded that human labour, even after the introduction of digitalization, is better suited to perform certain processes and are more qualified to make certain decisions than the cyber system [6,7]. It is important to exploit the potential of digitalization, but it must only be introduced with and through people, as people must take full responsibility for, manage and supervise the machines.

There is a great fervour in discussing digitalization, especially in the current context. The pandemic initiated an extensive and dramatic digital transformation in the society, forcing a digital leap in our everyday life, business and education [8].

There is a sophistication and coolness about it. We believe that things must be seen separately, there are situations in which technology helps a lot, as detailed above, but when we talk about virtual education and training done via Zoom or similar platforms, all this communication between teacher and student is completely broken. Many public figures argued against distance learning and training. Even though the technical conditions are met, the act of training and education is badly altered. That non-verbal language matters a lot. No technology can replace interpersonal relationships yet. Moreover, there is a solemnity of the act of education that cannot be preserved through digitalization and has an extremely important role in the process itself, in the trust that students have in the teachers and trainers. The whole process can turn into a cold and impersonal act. It is therefore impossible to give up the classic approach, but many educational activities can be performed via digitalization. Digital technology is clearly helping the process of education; therefore, it has to remain a complementary component of the educational and training system, not an alternative. 


\section{Focus Group on the Digitalization of Qualified Vocational Training}

Due to the current situation, which is characterized by limitations, the research process had to be adapted to actual conditions. The research methodology included a focus group on the digitalization of qualified vocational training, a focus group which eventually took place following all the rules of social distancing.

A focus group a discussion between people from similar backgrounds or experiences where they discuss a specific topic. It is a qualitative research where people are asked about their beliefs, opinion or ideas [9]. A focus group is a group of six to ten people led through by a skilled moderator. The group needs to be large enough to generate rich discussion but not so large that some participants are left out.

This focus group consisted of six professionals and a moderator who conducted the focus group. The participant were all teachers, from various technological high schools, amongst them: 3 headmasters, 1 teacher-senior member of the National Corps of Experts in Educational Management, and 2 engineers-one is the head of the engineering department and the other one is the coordinator of continuous training programs in one of the schools.

Obviously, all the participants were asked to share their opinion and ideas on the digitalization of qualified vocational training. The main question was related to how they see the development of education and vocational training in the context of digitalization. Participants shared their opinions, experience and challenges. A resume of the main expressed views is reported below:

P1 "As a manager and engineer, I cannot help but consider digitalization to be essential in the development of education and training. The supply of vocational education in the 21st century must be based, to a greater extent, on the digital aspect. We want to become a regional technology center and one of the best ways is to exploit the potential of digitalization."

P2 "The digitalization of education seems to be a priority currently at EU level and I hope that we can take advantage of this wave of enthusiasm and attract important funds for the development of vocational education in Romania, education whose potential is far from being reached."

P3 "We are in the era of capitalism, so the economic environment dictates the necessary skills and competencies. We, the ones involved in the education system, need to create educational offers and programs in which the skills and competencies pursued, including digital ones, comply with the requirements. Cooperation with companies will be the new normal (it must be) because it is the most efficient way to keep up with rapid technological changes. This leads to the development of vocational education and training."

P4 "Our education system must develop and support the development of new educational programs better anchored to the reality of this era. The development of education and training must be enhanced by massive investments by the authorities, including in digitalization."

P5 "Digitalization is a very important issue in education and training because digitalization is synonymous with technology; the potential is enormous, but it depends a lot on future investments."

P6 "Training programs are about constant personal development. Moreover, we live in times when we must reinvent ourselves professionally. Digitization is the key that will help us become more efficient in the training process of the new generations."

Other questions were discussed as well, all related to the main theme of digitalization. As a result of the discussion, the group reached a general consensus about the main aspects, pros and cons related to this consistent challenge named digitalization.

When speaking about challenges, the general agreement was that the vocational education and training cannot be entirely digitalized as qualified vocational development has to maintain its traditional approach in order remain attractive. The labour market dictates the implementation of skills and competences through different study programs, however, the accreditations of new educational programs cost money. Co-financing of new specializations must be done with the help of interested companies. Subsidizing participating companies by the state is essential, imperative. The local 
companies are not interested in sustaining entire programs, unless motivated by the authorities. Efficiency is one of the big pros regarding digitalization, still, financing the rapid technological changes remains a big issue.

This study is one of the first conducted in Mures County, Romania, on the topic of digitization. We would like to thank all the participants for their professionalism and dedication.

\section{Conclusions}

In a such a dynamic economy, given the fact that the European Union wants to remain a sustainable and performant economy, vocational education and training must develop the skills and competences needed and demanded by the labour market. That is why vocational education and training, alongside the economy, have to become smart. Once the various economic sectors are updated from the technological point of view, the technological education must follow. A synergy has to be developed between the two. The major challenge of digitalization remains its cost and its constant need of updating. Also, at the moment, the technological gap between various economic sectors and the vocational education and training is vast.

Digitalization brings a series of advantages, making work easier, propelling technological improvement and innovation. The way we'll manage the future challenges may help us maintain the social and technological advantages. The appropriate adaptation of the qualified vocational training system to the new conditions is and will be essential in order to assure the trainee's employability and adaptability, qualities which are the most needed today and tomorrow. Sustainable development of a sector means not only considering the benefits but also the people, life and nature. Based on these aspects is appropriate to build various types of programs, including educational programs.

Author Contributions: M.M.V. enriched the article with bibliographical references. C.V. facilitated the writing of this research and approved some technical details, contributing with valuable input and ideas L.O.M. guided the research and approved the methodology. A.M.R. and A.S. organized the focus group while M.M.V. conducted the focus group and summarized the results. All authors have read and agreed to the published version of the manuscript.

Funding: This research received no external funding.

Conflicts of Interest: The authors declare no conflict of interest.

\section{References}

1. European Commission. A New Skills Agenda for Europe. Working Together to Strengthen Human Capital, Employability and Competitiveness. 2016. Available online: https://ec.europa.eu/transparency/regdoc/rep/1/ 2016/EN/1-2016-381-EN-F1-1.PDF (accessed on 9 August 2020).

2. Fleaca, E.; Stanciu, D.R. Digital-age Learning and Business Engineering Education-A Pilot Study on Students' E-skills. Procedia Manuf. 2019, 32, 1051-1057. [CrossRef]

3. ZF Corporate.ro. Available online: https://www.zfcorporate.ro/business-legal/alexandru-reff-deloitte-moduldigital-de-lucru-nu-presupune-doar-adoptia-tehnologiilor-ci-presupune-noi-modele-de-business18930533 (accessed on 9 August 2020).

4. European Commission. Available online: https://ec.europa.eu/commission/presscorner/detail/en/ip_20_940 (accessed on 14 August 2020).

5. ZF Corporate.ro. Available online: https://www.zfcorporate.ro/mediafax-ro/economic/studiu-lucrand-acasaangajatii-simt-lipsa-interactiunii-sociale-si-a-19169382 (accessed on 14 August 2020).

6. Prinz, C.; Kreggenfeld, N.; Kuhlenkötter, B. Lean meets Industrie 4.0-A practical approach to interlink the method world and cyber-physical world. Procedia Manuf. 2018, 23, 21-26. [CrossRef]

7. Windelband, L. Zukunft der Facharbeit im Zeitalter "Industrie 4.0". JOTED 2014, 2, 138-160.

8. Iivari, N.; Sharma, S.; Ventä-Olkkonen, L. Digital transformation of everyday life-How COVID-19 pandemic transformed the basic education of the young generation and why information management research should care? IJIM 2020, 55, 102183. [CrossRef] 
9. Herd Organization. Available online: https://www.herd.org.np/uploads/frontend/Publications/Publications Attachments1/1485497050-Focus\%20Group\%20Discussion_0.pdf (accessed on 30 August 2020).

Publisher's Note: MDPI stays neutral with regard to jurisdictional claims in published maps and institutional affiliations.

(C) 2021 by the authors. Licensee MDPI, Basel, Switzerland. This article is an open access article distributed under the terms and conditions of the Creative Commons Attribution (CC BY) license (http://creativecommons.org/licenses/by/4.0/). 